of a positive IFN-score, confirming an activation of this inflammatory pathway, may guide the clinicians in the management of these patients and may support therapeutic decisions

Disclosure of Interests: : Silvia Federici: None declared, Gian Marco Moneta: None declared, Chiara Passarelli: None declared, Claudia Bracaglia: None declared, Carmela Gerarda Luana Raffaele: None declared, Fabrizio De Benedetti Grant/research support from: Abbvie, SOBI, Novimmune, Roche, Novartis, Sanofi, Pfizer, Antonella Insalaco: None declared DOI: 10.1136/annrheumdis-2019-eular.6128

\section{FRI0543 EFFICACY AND SAFETY OF INTRAVENOUS GOLIMUMAB IN PATIENTS WITH JUVENILE IDIOPATHIC ARTHRITIS: RESULTS FROM A PHASE 3 OPEN-LABEL STUDY}

Nicolino Ruperto ${ }^{1}$, Alberto Spindler ${ }^{2}$, Cesar Francisco Pacheco Tena ${ }^{3}$, Ingrid Louw ${ }^{4}$, Gabriel Vega Cornejo ${ }^{5}$, Daniel Kingsbury ${ }^{6}$, Michael Clark $^{7}$, Karen Bensley ${ }^{7}$, LI Xiaoming ${ }^{7}$, Hermine Brunner ${ }^{8}$, Investigators of the PRCSG and PRINTO networks. ${ }^{1}$ Istituto Giannina Gaslini, Pediatria II, Genoa, Italy; ${ }^{2}$ Centro Médico Privado de Reumatología, San Miguel de Tucuman, Argentina; ${ }^{3}$ Universidad Autónoma de Chihuahua, Chihuahua, Mexico; ${ }^{4}$ Panorama Medical Centre, Cape Town, South Africa; ${ }^{5}$ Hospital México Americano, Guadalajara, Mexico; ${ }^{6}$ Randall Children's Hospital at Legacy Emanuel, Portland, United States of America; ${ }^{7}$ Janssen Research and Development, LLC, Spring House, United States of America; ${ }^{8}$ Cincinnati Children's Hospital Medical Center, Cincinnati, United States of America Objectives: To assess efficacy \& safety of intravenous golimumab in pediatric patients with active polyarticular course juvenile idiopathic arthritis despite methotrexate therapy through 28 weeks of treatment.

Methods: A multicenter, Phase 3, single arm, open-label trial was conducted using intravenous golimumab at a dose of $80 \mathrm{mg} / \mathrm{m}^{2}$ given at weeks 0 \& 4, then every 8 weeks thereafter, in pediatric patients ages 2-17 years old with active polyarticular course juvenile idiopathic arthritis despite methotrexate therapy. Patients received commercial MTX weekly at same BSA-based dose as at time of study entry. All the results below are based on full analysis set which includes all patients who received at least 1 dose of study agent.

Results: 180 patients were screened (130 enrolled, 127 treated) with the first patient screened on 22Dec2014; last patient first treated 26Dec2017, \& last patient's Wk28 visit was 09Jul2018.

Proportion of JIA ACR 30,50,70, \& 90 responders at Wk28 was $83.5 \%, 79.5 \%, 70.1 \%$, \& $46.5 \%$, respectively. $29.1 \%$ of patients met criteria for inactive disease at Wk28. Median change from baseline for JASDAS 10,27 , \& 71 was $-14.20,-16.60$, \& -20.32 , respectively at Wk28. JADAS $10,27, \& 71$ minimal disease activity was met by $15 \%$ of patients at Wk28.

Proportion of patients experiencing at least 1 treatment-emergent $A E$ through Wk28 was $77.2 \%$. MedDRA system organ class with highest incidence of AEs was Infections \& infestations (57.5\%);most commonly reported $\mathrm{AE}$ upper respiratory tract infection(17.3\%), then nasopharyngitis (15.0\%).Six patients experienced serious AEs through Wk28: Herpes zoster disseminated, Infective exacerbation of bronchiectasis, Sepsis, Varicella, Mycosis fungoides, \& Suicidal ideation. These events resulted in permanent discontinuation of intravenous golimumab, except for Varicella. Conclusion: Intravenous golimumab delivered at a dose of $80 \mathrm{mg} / \mathrm{m} 2$ at weeks 0 \& 4, then every 8 weeks thereafter and appears to be effective in these patients with a safety profile similar to other TNF inhibitor therapies.

Disclosure of Interests: Nicolino Ruperto Grant/research support from: The Gaslini Hospital, where NR works as full-time public employee, has received contributions (> 10.000 USD each) from the following industries in the last 3 years: BMS, Eli-Lilly, GlaxoSmithKline, F Hoffmann-La Roche, Janssen, Novartis, Pfizer, Sobi. This funding has been reinvested for the research activities of the hospital in a fully independent manner, without any commitment with third parties., Consultant for: Received honoraria for consultancies or speaker bureaus (< 10.000 USD each) from the following pharmaceutical companies in the past 3 years: Ablynx, AbbVie, Astrazeneca-Medimmune, Biogen, Boehringer, Bristol-Myers Squibb, Eli-Lilly, EMD Serono, GlaxoSmithKline, Hoffmann-La Roche, Janssen, Merck, Novartis, Pfizer, R-Pharma, SanofiServier, Sinergie, Sobi and Takeda., Speakers bureau: Received honoraria for consultancies or speaker bureaus (< 10.000 USD each) from the following pharmaceutical companies in the past 3 years: Ablynx, AbbVie, Astrazeneca-Medimmune, Biogen, Boehringer, Bristol-Myers Squibb, Eli-Lilly, EMD Serono, GlaxoSmithKline, Hoffmann-La Roche, Janssen, Merck, Novartis, Pfizer, RPharma, SanofiServier, Sinergie, Sobi and Takeda., Alberto Spindler: None declared, Cesar Francisco Pacheco Tena Grant/research support from: Janssen Research \& Development, LLC, Ingrid Louw Consultant for:
Advisory committee: Roche, Novartis, Pfizer, Gabriel Vega Cornejo Grant research support from: I currently have no conflicts of interest, I am only setting protocols for the pharmaceutical industry with Parexel, Sanofi and Bristol-Myers Squibb., Daniel Kingsbury Grant/research support from: Clinical trial support from Bristol-Myers Squibb, Michael Clark Shareholder of: Johnson \& Johnson, Employee of: Janssen Research \& Development, LLC, Karen Bensley Shareholder of: Johnson \& Johnson, Employee of: Janssen Research \& Devvelopment, LLC, Xiaoming Li Shareholder of: Johnson \& Johnson, Employee of: Janssen Research \& Development, LLC, Hermine Brunner Grant/research support from: Bristol-Myers Squibb, Pfizer, Consultant for: Pfizer, Bristol-Myers Squibb, Janssen, Novartis, Lilly, Roche, GlaxoSmithKline, Sanofi, Speakers bureau: Novartis, Roche DOI: 10.1136/annrheumdis-2019-eular.333

\section{FRI0544 EFFICACY AND SAFETY OF CANAKINUMAB IN SYSTEMIC JUVENILE IDIOPATHIC ARTHRITIS EXPERIENCE USING DATA OF THE BIKER REGISTRY}

Gerd Horneff ${ }^{1,2}$, Eggert Lilienthal ${ }^{1}$, Ralf Trauzeddel ${ }^{1}$, Toni Hospach ${ }^{1}$, Tilmann Kallinich ${ }^{1}$, Frank Dressler ${ }^{1}$, Michaela Sailer-Hoeck ${ }^{1}$, Gerd Ganser ${ }^{1}$, Frank Weller-Heinemann ${ }^{1}$, Georg Heubner ${ }^{1}$, Andreas Urban ${ }^{1}$, Michael Rühlmann ${ }^{1}$, Christoph Rietschel ${ }^{1}$, Markus Hufnagel ${ }^{1}$, Wolfgang Emminger ${ }^{1}$, Ariane Klein ${ }^{1}$. ${ }^{1}$ BIKER-Registry, Sankt Augustin, Germany; ${ }^{2}$ Asklepios Clinic Sankt Augustin, General Paediatrics, Sankt Augustin, Germany

Background: Canakinumab is approved for the treatment of systemic juvenile idiopathic arthritis (SJIA) older than 2 years.

Objectives: The aim of the German Biologics Registry (BiKeR) is the surveillance of JIA patients exposed to biologics.

Methods: Baseline demographics and disease activity parameters were documented. Efficacy was determined using the JADAS and the proposed criteria for inactive disease on medication. Safety assessments were based on reports of adverse events $(A E)$. All reports have been coded according to MedDRA ${ }^{\circledR}$.

Results: 48 SJIA patients with 82.5 patient-years (PY) of exposure to Canakinumab were recorded in the German BiKeR registry. The tota observation time (from date of first dose until last follow-up, censored, if another biologic was started) was calculated with 109.9 PY.

The cohort treated with Canakinumab had experienced long disease dura tion of $2.9+/-3.8$ years (mean +/- SD). 21 (44\%) were pre-treated with methotrexate, 10 (21\%) with Etanercept, 3 (6\%) with Adalimumab, 18 $(38 \%)$ with Anakinra and $19(40 \%)$ with Tocilizumab. Concomitantly, 9 $(18.8 \%)$ received methotrexate, 22 (45.8\%) NSAIDs and $23(48 \%)$ systemic corticosteroids.

At last follow up upon treatment, $48 \% / 44 \% / 42 \% / 38 \%$ of patients reached PedACR30/50/70/90 improvement. 8 patients (16.7\%) had inactive disease according to the Wallace criteria. The median (IQR1-IQR3) JADAS10 score decreased from $12.6(6.2-15.8)$ at baseline to $0.5(0.0-2.8)$. During ongoing treatment, approximately $82 \%$ of patients achieved a JADAS defined minimal disease activity; while 64\% reached a JADAS defined remission at last follow-up.

125 adverse events (AE) were recorded (114 events/100PY $[95 \% \mathrm{Cl} 96$ 136]). Of these, 22 qualified as serious adverse events (SAE) (20/100PY [13-30]). 100 AEs were observed during exposure or up to 90 days follow up after the last exposure to Canakinumab (121/100PY [99-147]). 19 qualified as SAE (23/100PY [15-36]).

Adverse Events of Special Interest were serious and medically important infection $(n=4)$, cytopenia $(n=4)$, macrophage activation syndrome $(n=3)$ There was no opportunistic infection, intestinal perforation, anaphylaxis or other hypersensitivity, thrombotic event, evolving autoimmune disease, cardiac or cerebral event, bleeding, malignancy, or death. A total of 38 patients $(79 \%)$ discontinued treatment, $8(17 \%)$ due to lack or efficacy, $16(33 \%)$ due to remission and $2(4 \%)$ because of intolerance.

Conclusion: The current analysis adds to the established safety profile of Canakinumab and demonstrates that safety was comparable and consis tent with the overall $A E$ profile of Canakinumab in paediatric patients. MAS occurred in three SJIA patients and might be a JIA-associated feature. Infections were the most frequent $A E$, but only two serious infections were reported. No new safety signals specific to the paediatric population were identified for Canakinumab; the risk profile of Canakinumab remains positive for the approved paediatric indication SJIA.

\section{REFERENCES:}

[1] Horneff G, Klein A, Klotsche J, Minden K, Huppertz HI, Weller-Heinemann F, Kuemmerle-Deschner J, Haas JP, Hospach A. Comparison of treatment response, remission rate and drug adherence in polyarticular juvenile idio pathic arthritis patients treated with etanercept, adalimumab or tocilizumab. Arthritis Res Ther. 2016 Nov 24;18(1):272 


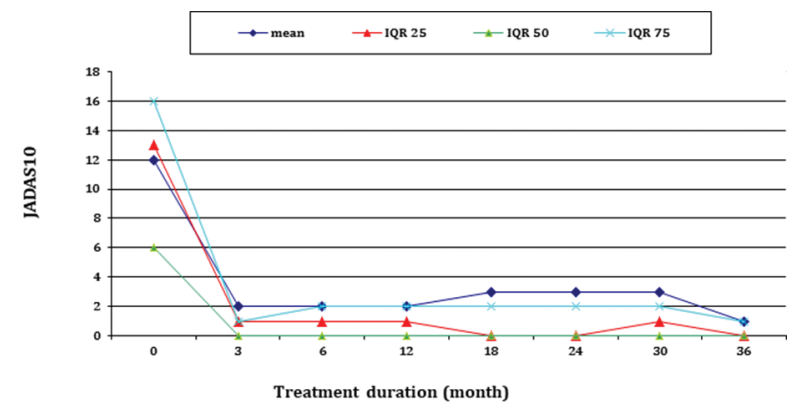

Acknowledgement: The authors acknowledge all contributors to BIKER, patients, parents and study staff

Disclosure of Interests: Gerd Horneff: None declared, Eggert Lilienthal: None declared, Ralf Trauzeddel: None declared, Toni Hospach Speakers bureau: Chugai, Roche, Novartis, Tilmann Kallinich Grant/research support from: Novartis, Speakers bureau: Sobi, Roche, Novartis, CLB, Frank Dressler Paid instructor for: Abbvie, Pfizer, Novartis, Michaela SailerHoeck: None declared, Gerd Ganser: None declared, Frank Weller-Heinemann: None declared, Georg Heubner: None declared, Andreas Urban: None declared, Michael Rühlmann: None declared, Christoph Rietschel: None declared, Markus Hufnagel: None declared, Wolfgang Emminger: None declared, Ariane Klein: None declared

DOI: 10.1136/annrheumdis-2019-eular.1429

\section{FRI0545 HEMODYNAMIC MEASUREMENTS AND ARTERIAL STIFFNESS IN PATIENTS WITH JUVENILE IDIOPATIC ARTHRITIS COMPARED TO CHILDREN WITHOUT JUVENILE IDIOPATIC ARTHRITIS}

Jorge E. Rubio Silveira ${ }^{1}$, C. Araceli Arellano Valdez ${ }^{1}$, Carlos Ramos Becerra ${ }^{2}$, Myriam Mendez Nuñez ${ }^{1}$, David Cardona Müller ${ }^{2}$, Oscar Mares Flores ${ }^{2}$, Priscila Vega García ${ }^{2}$, Fernando Grover Páez ${ }^{2}$, Alberto Tlacuilo Parra ${ }^{3} .{ }^{1}$ Instituto Mexicano del Seguro Social. Centro Médico Nacional de Occidente, Pediatric Rheumatology, Guadalajara, Mexico; ${ }^{2}$ Universidad de Guadalajara, Vascular Mechanics, Guadalajara, Mexico; ${ }^{3}$ Instituto Mexicano del Seguro Social. Centro Médico Nacional de Occidente, Research Chief, Guadalajara, Mexico

Background: Juvenile Idiopathic Arthritis (JIA) can cause long-term cardiovascular complications. There are non-invasive, validated, easy to perform methods for cardiovascular testing, such as: carotid intimal-media thickness (CIMT), and measurement of arterial rigidity through carotid distensibility, carotid-femoral pulse wave velocity (cfPWV) and the augmentation index (Alx).

Objectives: To compare the main hemodynamics measurements (cIMT, carotid distensibility, cfPWV and Alx) between JIA and non-JIA subjects. Methods: Analytical cross-sectional study in subjects 5 to 16 years of age. Two groups: patients with JIA according to the ILAR classification without any other condition vs healthy children. Measurements: somatometry, laboratory (glucose, creatinine, lipid profile), disease activity index (JADAS-27) and hemodinamic variables (cIMT, carotid distensibility, cfPWV and Alx).

Results: $63 \mathrm{JIA}$ subjects and 50 healthy controls were included, mean age $11.5 \pm 2.8$ vs $10.7 \pm 3.2$ years $(p=0.17)$ and $70 \%$ vs $54 \%$ females, respectively. Both groups were also similar $(p>0.05)$ for nutritional state, sedentary lifestyle, smoking habits and family history of cardiovascular risk. Table 1 show lipid profile of both groups. Subtypes of JIA were: RF positive polyarthritis (29\%), RF negative polyarthritis (29\%), oligoarthritis $(19 \%)$, enthesitis-related arthritis $(14 \%)$ and systemic arthritis $(9 \%)$. Mean time of disease evolution was $4 \pm 3$ años. There were no significant differences between groups in the main hemodinamic parameters (table 2). When comparing inactive vs active disease and active disease vs controls there were no differences either, we found a discrete trend to less carotid distensibility and higher cfPWV in patients with active disease compared to controls $[0.63 \pm 0.17 \mathrm{~mm}$ vs $0.66 \pm 0.15$ $\mathrm{mm}(p=0.94)$ and $6.12 \pm 2.88 \mathrm{~m} / \mathrm{s}$ vs $5.42 \pm 0.75 \mathrm{~m} / \mathrm{s}(p=0.33)$, respectively]. $59 \%$ of subjects with JIA were inactive according to JADAS-27. When considering time of disease evolution, children with 0-4 years vs children with $>4$ years and children with $>4$ years vs controls, we found differences in cIMT $[0.41 \pm 0.62 \mathrm{~mm}$ vs $0.44 \pm 0.50 \mathrm{~mm}(\mathrm{p}=$ $0.02)$ and $0.44 \pm 0.50 \mathrm{~mm}$ vs $0.40 \pm 0.70 \mathrm{~mm}(p=0.01)$, respectively].
Finally, cfPWV was higher in patients with $0-4$ years than in patients with $>4$ years of evolution $(p=0.01)$

TABLE 1. LIPID PROFILE

\begin{tabular}{lccc}
\hline LIPID & JIA & CONTROLS & $p_{\dagger}^{\dagger}$ \\
\hline Triglicerides & $94 \pm 56$ & $85 \pm 36$ & 0.22 \\
Total & $141 \pm$ & $152 \pm 26$ & 0.06 \\
cholesterol & 27 & & \\
HDL cholesterol & $45 \pm 12$ & $47 \pm 10$ & 0.36 \\
LDL cholesterol & $77 \pm 21$ & $87 \pm 22$ & 0.01 \\
VLDL & $18 \pm 11$ & $17 \pm 7$ & 0.52 \\
cholesterol & & &
\end{tabular}

†Mann-Whitney U test.

TABLE 2. HEMODINAMIC MEASUREMENTS

\begin{tabular}{lccc}
\hline MEASUREMENT & JIA & CONTROLS & $p_{\dagger}^{\dagger}$ \\
\hline clMT (mm) & $0.42 \pm$ & $0.40 \pm 0.70$ & 0.11 \\
& 0.59 & & \\
Carotid distensibility & $0.64 \pm$ & $0.66 \pm 0.15$ & 0.78 \\
(mm) & 0.16 & & \\
cfPWV $(\mathrm{m} / \mathrm{s})$ & $5.77 \pm 2$ & $5.42 \pm 0.75$ & 0.66 \\
Alx $(\%)$ & $69 \pm 15$ & $69 \pm 12$ & 0.64 \\
\hline
\end{tabular}

"Mann-Whitney U test.

Conclusion: We found a tendency to increased cardiovascular risk when the disease has more than 4 years of evolution, specially in patients with persistent active disease. Traditional and non-traditional cardiovascular risk factors add up in this population. We need longterm follow-up studies.

\section{REFERENCES:}

[1] Bohr AH, Fuhlbrigge RC, Pedersen FK, De Ferranti SD, Müller K. Premature subclinical atherosclerosis in children and young adults with juvenile idiopathic arthritis. A review considering preventing measures. Pediatr Rheumatol 2016; 14: 1-5.

[2] Sozeri B, Atikan BY, Ozdemir K, Mir S. Assessment of vascular function in systemic onset juvenile idiopathic arthritis. Clin Rheumatol 2016; 35: 16991703.

Disclosure of Interests: Jorge E. Rubio Silveira Grant/research support from: Grants from Roche and Abbvie for some national meetings, C. Araceli Arellano Valdez Grant/research support from: Grants from Roche for multiple national and international meetings., Speakers bureau: different conferences about Tocilizumab in meetings., Carlos Ramos Becerra: None declared, Myriam Mendez Nuñez: None declared, David Cardona Müller: None declared, Oscar Mares Flores: None declared, Priscila Vega García: None declared, Fernando Grover Páez: None declared, Alberto Tlacuilo Parra: None declared DOI: 10.1136/annrheumdis-2019-eular.4549

\section{\begin{tabular}{|l|l}
\hline FRI0546 TRAJECTORIES OF DISEASE ACTIVITY OVER THE \\
\hline
\end{tabular} FIRST THREE YEARS FOLLOWING JUVENILE IDIOPATHIC ARTHRITIS DIAGNOSIS}

Stephanie Shoop-Worrall ${ }^{1,2}$, Kimme Hyrich $^{2,3}$, Lucy Wedderburn ${ }^{4,5,6}$ Wendy Thomson ${ }^{3,7}$, Nophar Geifman ${ }^{1,8}{ }^{1}$ The University of Manchester, Centre for Health Informatics, Manchester, United Kingdom; ${ }^{2}$ The University of Manchester, Arthritis Research UK Centre for Epidemiology, Manchester, United Kingdom; ${ }^{3}$ Central Manchester University Hospitals NHS Foundation Trust, Manchester Academic Health Science Centre, NIHR Manchester Musculoskeletal BRC, Manchester, United Kingdom; ${ }^{4}$ GOS Institute of Child Health, University College London, Arthritis Research UK Centre for Adolescent Rheumatology, London, United Kingdom; ${ }^{5}$ Great Ormond Street Hospital NHS Foundation Trust, Paediatric Rheumatology, London, United Kingdom; ${ }^{6}$ NIHR Great Ormond Street Hospital Biomedical Research Centre, London, United Kingdom; ${ }^{7}$ The University of Manchester, Arthritis Research UK Centre for Genetics and Genomics, Manchester, United Kingdom; ${ }^{8}$ The University of Manchester, The Manchester Molecular Pathology Innovation Centre, Manchester, United Kingdom

Background: The advent of biological therapies and early aggressive treatment strategies have drastically changed prognoses for children and young people (CYP) with juvenile idiopathic arthritis (JIA). Clinical trials and observational research have demonstrated improvements in disease for the majority, but not all, CYP over time. It is not currently known what the patterns of disease activity are in CYP with JIA and how these cluster over time. 